\title{
Modern Management of Maxillofacial Injuries
}

\author{
Gabriele Canzi, Davide Sozzi, and Alberto Bozzetti
}

\section{Key Points}

- Bleeding after facial trauma is often self-limiting and life-threatening only in $1.4-11 \%$ of all severe facial injuries. Its prompt identification and timely management play a major role in ensuring safe access to airways and in avoiding increased blood loss with hemodynamic worsening.

- Trauma surgeons should become increasingly confident with local hemostatic measures, which are fast effective in facial bleeding control and hemodynamic stabilization, delaying definitive treatments according to the damage control strategies.

- Each patient requiring total body or brain CT, with concomitant external evidence of facial involvement, must be studied with thin-slice CT scan and additional tridimensional reconstruction, especially in middle third, orbital, cranial base, or panfacial involvement.

- In modern trauma centers, diagnostic arteriography and superselective embolization (by coaxial microcatheter) is the gold standard definitive treatment of facial hemorrhages which are refractory to local measures.

- When $\mathrm{ABC}$ priorities are dealt with, visual-threatening conditions have to be detected early and promptly managed. They occur in $0.56-6 \%$ of facial fractures and orbital compartment syndrome is the most common one. Anterior orbitotomy by lateral canthotomy and inferior cantholysis is an easier, faster, and more effective decompressive treatment.
G. Canzi $(\square)$

Maxillofacial Departmental Structure, the Emergency Department, ASST Grande Ospedale Metropolitano Niguarda, Milan, Italy e-mail: gabriele.canzi@ospedaleniguarda.it

D. Sozzi

ASST Monza San Gerardo Hospital, and the Department of Medicine and Surgery, School of Medicine, University of

Milano-Bicocca, Milan, Italy

e-mail: davide.sozzi@unimib.it

\section{A. Bozzetti}

Maxillofacial Departmental Structure, the Emergency Department, ASST Grande Ospedale Metropolitano Niguarda, Milan, Italy

ASST Monza San Gerardo Hospital, and the Department of Medicine and Surgery, School of Medicine, University of Milano-Bicocca, Milan, Italy

e-mail: alberto.bozzetti@unimib.it 


\subsection{Introduction}

The importance of maxillofacial involvement in early management of trauma emergencies, following ATLS principles, lies in the matter that this life-threatening area is close to airways and the brain.

Moderate bleeding caused by facial trauma is frequent, but it is rarely one of the main causes of hemodynamic instability.

In addition, facial injuries are characteristically exposed for loss of specific sensory function, as in the case of visual involvement. This is another kind of emergency, as do as limb-threatening injuries, that must be promptly recognized and managed.

Other functional and morphological traumatic alterations, extremely relevant in facial trauma, are rarely a real priority.

Strict modern legislation regarding protection devices reduced overall incidence of facial injuries in road traffic accidents [1]; on the other hand, complex lesions increased because of a relatively greater number of high energy dynamics. However, most facial fractures occur in daily activities, followed by sports injuries and assaults. Selfinflicted lesions still remain less frequent but potentially devastating.

In 2016, according to the Niguarda Trauma Center Register in Milan, maxillofacial involvement concerns up to $25 \%$ of major trauma patients admitted to ER.

This demands an increased familiarity of trauma surgeons with identification and management of maxillofacial emergencies, among patients with multi-districtual and concomitant traumatic injuries.

\subsection{Airways and Breathing}

AB management (previously discussed in Chap. 10) can become exceedingly complex in facial trauma, because of bilateral and displaced mandibular fractures with glossoptosis, backward maxillary fractures with palatopharyngeal obstruction, oral swelling and hematomas, foreign bodies, missing teeth and dental prosthesis, and pharyngeal bleeding $[2,3]$.

Alcohol, drugs, and concomitant brain injury can cause nausea and vomiting and reduce protective reflexes. Laryngotracheal injury can further complicate definitive airways (orotracheal and nasotracheal intubation, surgical airway) which must be chosen in patients with facial bleeding to suggest aspiration over supraglottic devices.

In complex cranio-maxillofacial trauma, cervical spine fractures should always be considered unless it is proven otherwise. Their incidence ranges from 1 to $10 \%$ of all facial trauma [4]. Every attempt to protect airways needs to take this into account and must be performed with in-line stabilization; either can be hampered by hard cervical collar maintenance.

\subsection{Circulation}

\subsubsection{Clinical Assessment}

Bleeding after facial trauma is often self-limiting, particularly in patients with hypotension caused by concomitant hemorrhages from other sources. Thus, real life-threatening hemorrhages from facial fractures are very infrequent (from 1.4 to $11 \%$ of severe facial trauma) $[5,6]$.

Although a facial injury is the most noticeable, it rarely is an effective lifesaving priority [7].

Prompt identification and fast management of craniofacial bleeding play a primary role in ensuring safe access to airways and in avoiding increased blood loss, in the presence of other significant body lesions, with hemodynamic worsening.

However, its improvement, as well as fast local hemostasis, should never interfere with the team comprehensive acute care work-up, in patients with concomitant and multiple trauma injuries.

In any case, major trauma must be considered an evolving problem, and patients, after stabilization, have to be periodically reassessed to confirm treatment effectiveness, i.e., after normal hemodynamic parameters have been recovered.

Clinical evaluation starts by assessing specific evaluation about hemorrhagic risk, based on trauma dynamic analysis and then injury presumption, as well as the pharmacological and pathological anamnesis highlighting conditions which may lead to persistent bleeding. 


\subsubsection{Diagnosis}

Assessment in emergency room during primary survey is mainly clinically oriented to identify bleeding coming from soft tissues deep wounds, anterior epistaxis, and oral hemorrhages.

The supine position can mask posterior bleeding from oral or anterior nasal laceration, accumulated in the pharyngeal space. They have to be discovered through inspection and continuous suction of the pharynx, at the same time as the oral cavity evaluation to exclude possible displaced jaw fractures or mucosal lacerations.

Relatively conscious patients can blow blood stagnant in the pharynx, especially in moderate bleeding which can remain misdiagnosed for a long time with the late onset of vomiting and further risk for airways and "unclear" cervical lesions.

During the secondary survey, traditional radiology is obviously not indicated in complex facial fractures. Each patient who requires total body or brain $\mathrm{CT}$, with concomitant external evidence of facial involvement, must be studied with thin-slice CT scan with additional tridimensional reconstruction. This is diagnostic gold standard especially in patients with middle third, orbital, cranial base, or panfacial involvement. Contrast medium is unnecessary and no other additional information is given. Logically only stable or stabilized patients must be subject to CT.

\subsubsection{Operative Management}

\subsubsection{Local Measures}

Generally, local hemostatic measures are fast-acting in bleeding control and hemodynamic stabilization and allow diagnostic prosecution and patient transfer toward the IC unit, delaying definitive treatments according to damage control strategies.

Bleeding from deep, soft tissue wounds can be rapidly controlled by direct compression or by clamping any visible major vessel laceration. Wide and deep scalp flaps can be managed with compressive dressing or with handheld packing, 1-2/0 poly-filament stitches, or with temporary positioning of a Backhaus towel clamp.

In obvious middle third involvement with epistaxis, we recommend immediate anterior nasal packing with hemostatic self-expanding lubricated tampons (Merocel ${ }^{\circledR}$, Rapid Rhino $^{\circledR}$ ) (Fig. 12.1a).

In this way, we can anticipate direct hemostasis of anterior nasal lacerations of the Kiesselbach plexus, which are the most frequent causes of epistaxis (Fig. 12.1b).

During pharyngeal inspection, we can so appreciate the end of bleeding from posterior choanae or, alternatively, discriminate necessity of conversion into anterior-posterior nasal packing. That is rarely indicated in case of blood origin from posterior nasal space or cranial base fractures, accumulated in sphenoidal sinuses.
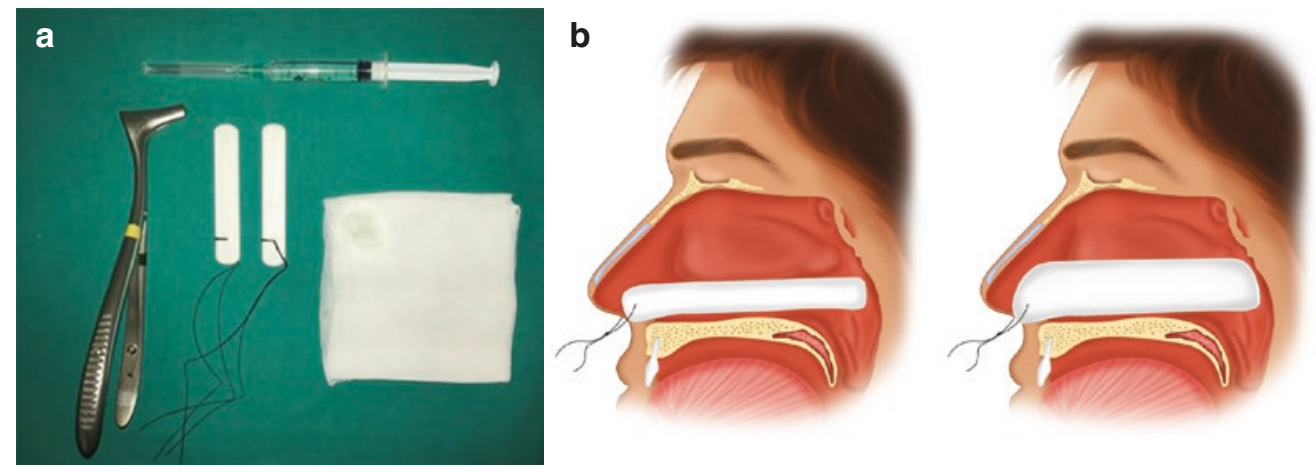

Fig. 12.1 (a) Devices needed to perform anterior nasal packing: nasal speculum and hemostatic nasal tampons. (b) Anatomic positioning of selfexpanding nasal tampons in anterior nasal packing; note the anterior security ligature 

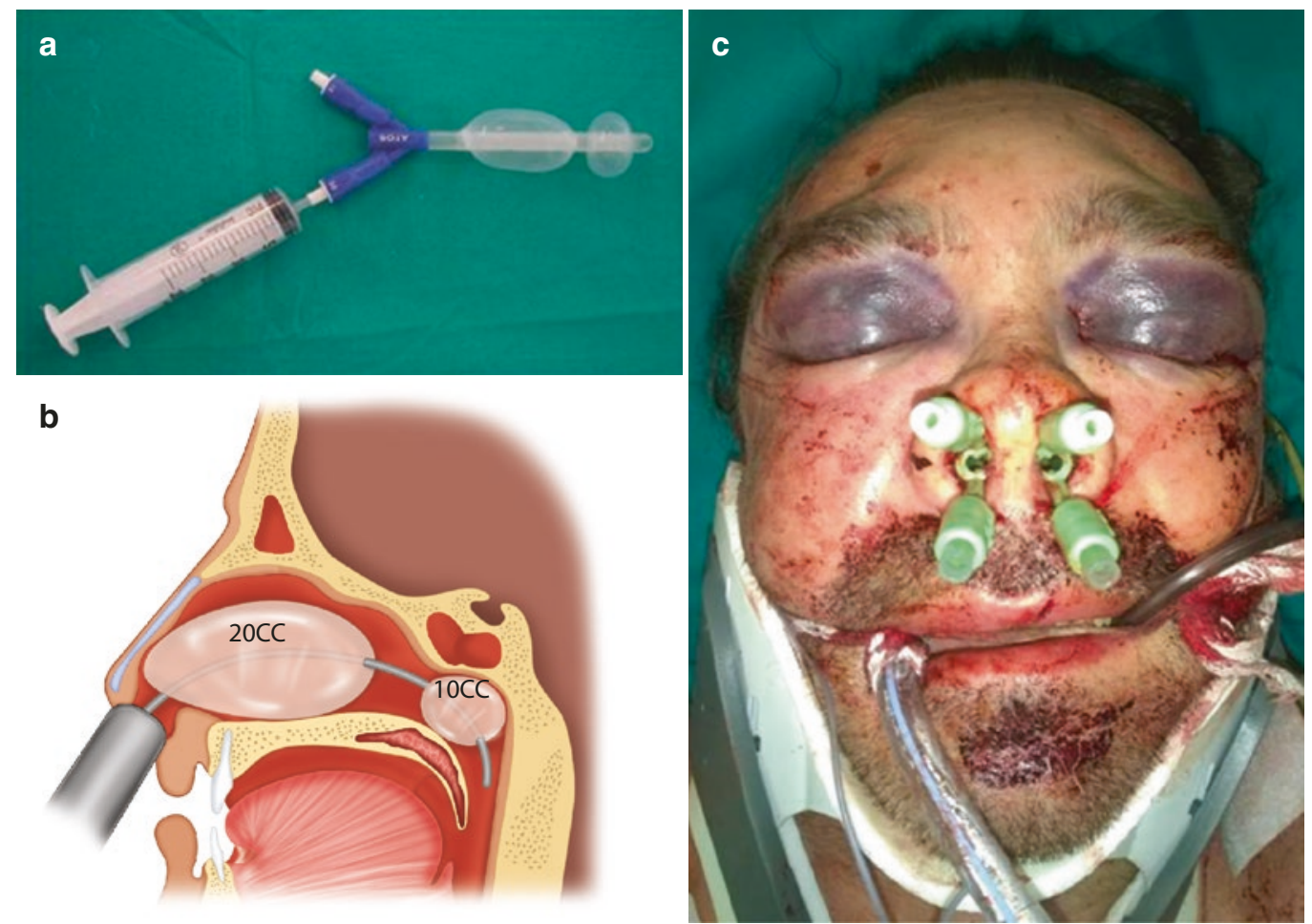

Fig. 12.2 (a) Devices needed to perform anterior-posterior nasal packing: Silicone dual lumen devices (Bivona ${ }^{\circledR}$ ) with separate inflating balloons. (b) Anatomic positioning of dual lumen catheter with double

In case of profuse rhino-oropharyngeal bleeding, if anterior-posterior nasal packing is immediately necessary, we suggest the use of modern silicone dual lumen devices $\left(\right.$ Bivona $^{\circledR}$ ), which can variably inflate (with air or physiological solution) separate balloons for the anterior and posterior nasal spaces (Fig. 12.2a).

Their positioning is fast, easy, and effective, with few reports in literature about its accidental intracranial ectopic placement, in patients with concomitant skull base injuries [8].

This enhances prudential attitude and formal contraindication in those patients with this kind of lesions that, however, more than any others, could benefit from these devices to save time toward definitive control of bleeding.

In our experience correct device positioning, if necessary to control copious bleeding, is a safety maneuver also in patients with cranial base fractures.

First clinicians have to adequately consider direction of nasal floor in supine patients, possibly with displaced upper jaw fractures. Safe position of silicone doubleballoon catheter needs to slide onto this anatomic guide. balloons; note the posterior balloon positioned beyond the posterior choana. (c) Clinical example of bilateral anterior-posterior nasal packing with this kind of device

When the posterior wall of pharynx is reached with the tip of the device, the posterior balloon (smaller in volume) is inflated first and progressively, keeping on hand the device and feeling a downward traction back to the choana (Fig. 12.2b).

If this helpful feeling is not clearly perceived, the device must be removed and positioning starts over. In difficult cases, an upper oropharyngeal tight packing with gauzes could temporarily replace posterior nasal packing.

After that, a gentle pulling of the silicone catheter allows one to anchor the choana and could help for forward reduction of backward dislocated LeFort maxillary fractures.

Concomitant upper jaw reduction is recommended with anterior balloon inflation that otherwise could worsen bone disimpaction and bleeding [6].

Finally, the anterior balloon (bigger in volume) is inflated until a patient-specific volume, needed to fulfill anterior nasal cavity until bleeding stops.

In the majority of cases, this procedure is performed bilaterally, and only after complete stabilization of vital 

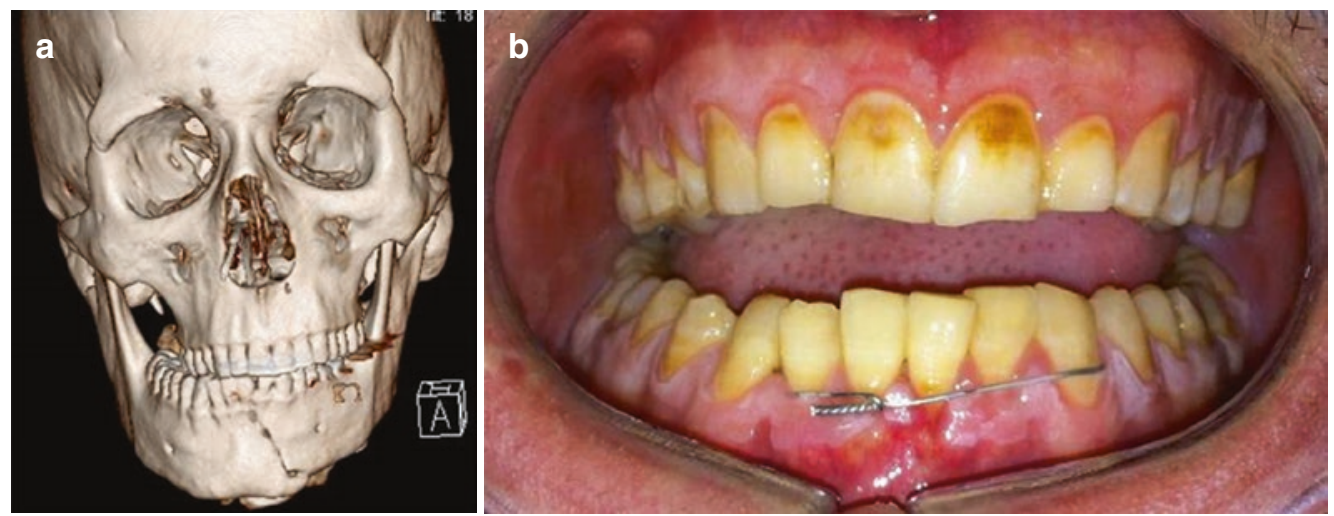

Fig. 12.3 (a) Unstable fracture of mandibular symphysis. (b) Temporary stabilization with iron interdental ligature, after manual reduction. Three teeth on the right and two teeth on the left of the fracture site were utilized

parameters and thin-slice CT scan analysis can one of the two be progressively removed (Fig. 12.2c).

If silicone devices with double balloons are unavailable, posterior nasal packing could be similarly made using a silicone urinary Foley catheter. Then traditional anterior nasal packing with tampons is completed.

After temporary control of external and pharyngeal bleeding, proceed with oral cavity inspection with adequate field illumination, rigid tongue depressors, and large caliberhigh flow rigid aspirators.

Mobile dental prosthesis must be removed, and empty dental alveolus checked, suggesting that teeth are avulsed and have to be located and removed with forceps to avoid pharyngeal dislocations.

Systematic oral cavity evaluation starts with upper and lower vestibular fornix inspection, moving to gingival mucosa, cheeks, and palate. After comes meticulous and bilateral inspection of the floor of the mouth, base of the tongue, and mobile tongue.

Not only do mucosal lacerations have to be checked, which are potential expressions of corresponding bone fractures, but so do oral floor of mouth hematomas since active bleeding could push back the tongue base causing impending airway obstruction.

All wounds beneath the submucosal plane have to be treated with temporary hemostatic suture with 3-4/0 catgut suture.

Plane reconstruction of muscle involvement or full thickness wounds could be delayed until stable vital parameters are guaranteed, complying with ATLS priorities in a timesaving manner.

Oral cavity inspection also allows identifying any bony exposure, corresponding to displaced fractures of the mandible or alveolar processes of upper and lower jaws. Bone margins can bleed with inadequate response to local manual compression, although they are rarely the main cause of real hemorrhages.

In these cases, definitive hemostasis is achieved with fracture reduction and temporary stabilization.

Fractures of tooth-bearing lower jaw segments could be stabilized with steel interdental ligatures, placed between mesial and distal teeth across the fracture site. Steel ligatures positioning between teeth just corresponding to the fracture is unadvisable because the ligatures often lose stability with an increased risk of avulsion and bleeding relapse.

At least the second ones on both fracture side are generally chosen. Steel wire is first passed between the teeth in a vestibular-to-lingual way and then in the opposite way, lingual-to-vestibular, on the other side. This creates a loop that embraces the internal surface of selected teeth, and it is secured by twisting the wire forceps in outer position, holding together two bone fragments (Fig. 12.3a, b).

This temporary stabilization also reduces pain and could help to protect airways, by keeping forward reduced bilateral mandibular fractures.

If there are no concomitant upper jaw fractures, this maneuver is performed, after gross manual reduction of bone fragments, keeping the patient in his individual occlusion (maximal intercuspidation between upper and lower dental arches). It allows further reduction with bone margin compression and hemostatic optimization.

In partially edentulous patients or multiple traumatic teeth avulsion, stabilization can be achieved with dental arch bars positioning that involves at least three elements for each side.

Upper alveolar fractures with bleeding from margins are managed similarly with manual reduction and temporary steel ligature. 


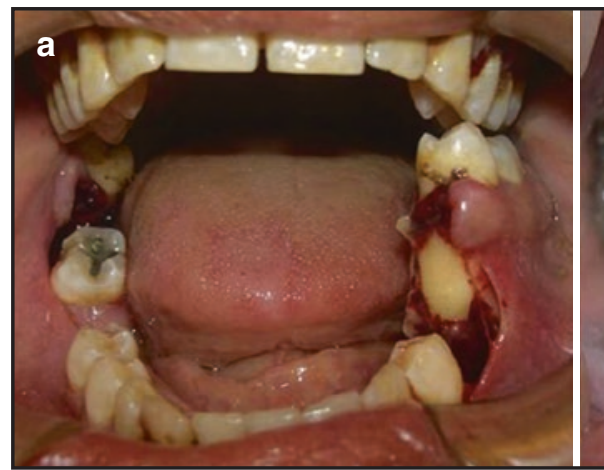

Fig. 12.4 (a) Bilaterally displaced fractures of the posterior mandibular body, with exposition, mucosal laceration, and bleeding. (b) Faster stabilization with intermaxillary fixation, performed by matching sin-

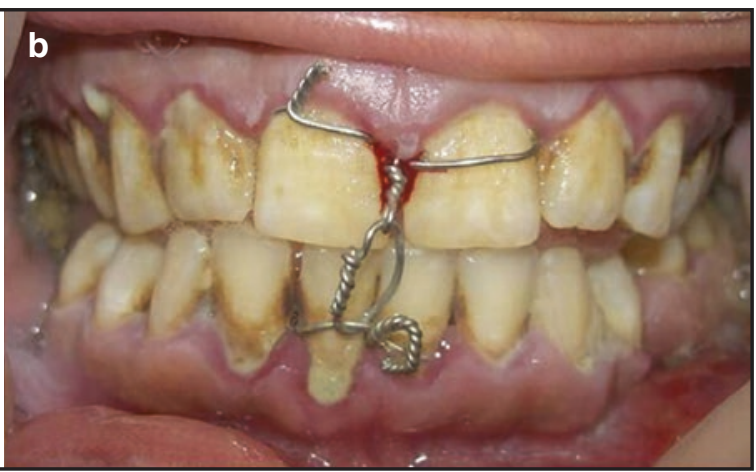

gle median upper and lower interdental ligatures; oral cavity and orotracheal accesses are now avoided
Bleeding originating from mandibular angle fractures or LeFort fractures of the upper jaw needs reduction and stabilization with intermaxillary fixation (IMF) with arch bars or interdental ligatures (Fig. 12.4a, b).

IMF positioning obviously interferes with oral cavity inspection and access to airways. Thus, its use is recommended only in patients with definitive airways (nasotracheal or surgical, orotracheal if tube can be placed in retromolar or edentulous sites).

In patients with bleeding from displaced midfacial fractures and no definitive airways, a mouth prop can help to maintain reduction.

In the emergency room, the need for fracture stabilization with a time-consuming procedure (i.e., plate and screws positioning or external fixation) is extremely rare.

At this stage, oronasal bleeding must be controlled, and acute care surgeon can go back to soft tissue laceration, previously temporarily treated with packing or compressive dressing.

Major vessel damages must be clipped or ligated if not already done; each wound could be managed with diathermy or faster full thickness (including the aponeurosis layer in scalp lacerations) running suture, and each definitive treatment must be ideally delayed.

All tasks (identification of bleeding points, hemostasis, and efficacy observation) should be performed in a few minutes, as should further "C"'-control of hemorrhages, without any delays for the workflow of the team.

At this time no specific diagnostic imaging is needed, and every maneuver is based on clinical evidence.

\subsubsection{Definitive Control of Bleeding}

These local hemostatic measures are adequate to manage facial bleeding in most trauma patients [9]. The rule is:
"When hypovolemic shock is present, facial injuries are unlikely to be the sole cause" $[10,11]$.

However, massive facial hemorrhage has been reported to occur in up to $10 \%$ complex facial injuries $[5,6,12,13]$ and can cause itself hypovolemic shock in only $1.4 \%$ of these cases $[9,14]$, but the calculated mortality rate is $20.21 \%$ of these cases [9].

It is in major midface and panfacial injuries that blood loss can quickly become significant and refractory to local measures [15]; these account for $2-4 \%$ of all facial bleeding that arise from the maxillary artery or its branches, ethmoidal artery, ophthalmic artery, or Vidian branch of internal carotid artery [4] or rarely from skull base fractures with direct internal carotid artery involvement $[16,17]$.

Literature has identified anterior-posterior nasal packing as the initial management; it controls bleeding in $29 \%$ of patients and reduces it in another $44 \%$ of patients $[10,15,18]$.

This would allow obtaining hemodynamic response to volemic resuscitation, necessary to go on with diagnostic tools or toward the definitive treatment of bleeding.

Historically the life-threatening facial bleeding which was refractory to local measures was managed with external carotid artery ligation [19], but internal and external carotid arteries are associated with extensive collateral circulation and bilateral communication, leading to faster relapse of bleeding [13].

Point of artery ligation is critical and by ligating the external carotid artery at its origin is ineffective in controlling hemorrhage, due to its extensive collateral circulation [9].

Thus, the artery ligation must be done bilaterally [20] or just corresponding to the bleeding point, in order to reduce relapses from collateral recruitment $[16,21]$. 

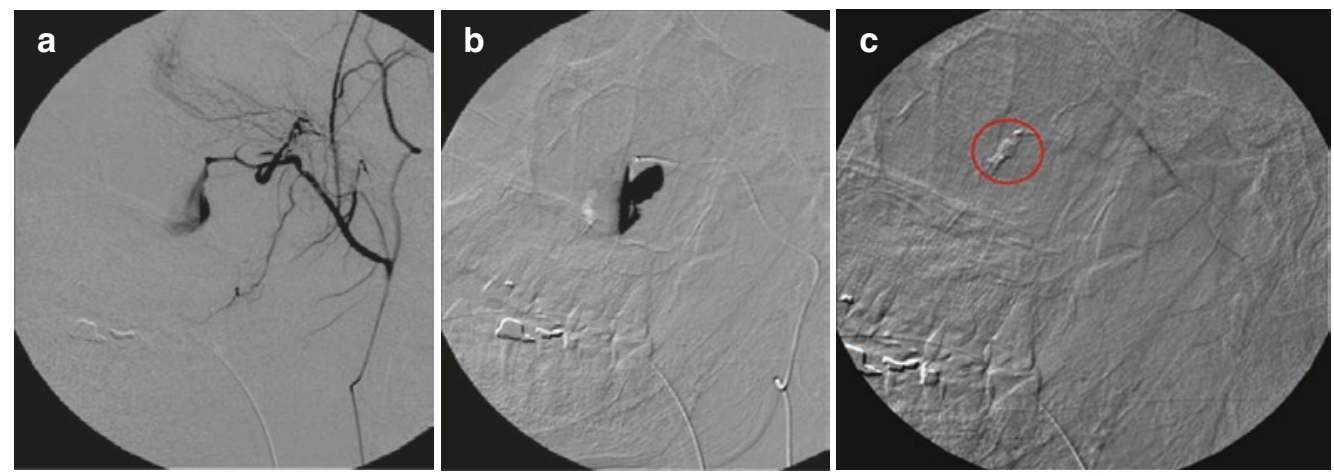

Fig. 12.5 (a) Right internal maxillary artery selective arteriography in complex middle third facial fracture with epistaxis refractory to local measures. Note extravasation of contrast medium into right maxillary sinus, coming from small ramification of internal maxillary artery. (b)

Sakamoto et al. found that catheter balloon tamponades and external carotid ligation cannot respond in over $72 \%$ to massive epistaxis [22].

In $70 \%$ of cases of traumatic intractable epistaxis, the internal maxillary artery, or one of its branches, is injured [9, 23]. That's why transantral ligation of the internal maxillary artery was described [24, 25].

Nevertheless, the anatomy complexity of the bony midface can make direct ligation of the bleeding point virtually impossible, especially in patients with torrential bleeding, nasal tamponade, and unclear neck involvement $[13,26]$.

For the same reasons angio-CT has no role in diagnostic work-up of facial hemorrhages which are refractory to local measures; peripheric small caliber ramification of facial vessels and bone comminution in naso-sinusal complex fractures make contrast blush unidentifiable. Thus, angio-CT remains time-consuming and it is usually skipped, proceeding with the angiographic suite. Also, preliminary and comprehensive evaluation of supra-aortic vessel anatomy could be better studied by arteriography.

A diagnostic arteriography and superselective embolization, aided by a coaxial microcatheter, has definitively replaced external carotid artery ligation in modern trauma centers, where this approach is available $[4,9,13,18,27-30]$ (Fig. 12.5).

Transarterial embolization of internal maxillary artery for intractable epistaxis was first reported by Sokoloff et al. in 1974 [31]; since then many reports have suggested a success rate between 70 and $100 \%$. The resolution of bleeding was often immediate and stable [5, 9-11, 13, 18, 22-24, 27, $32,33]$.

The advantages are a less invasive procedure, faster control of bleeding even from multiple and surgically inac-
2F coaxial microcatheter reaching exactly the bleeding point. (c) Cyanoacrylate-Lipiodol deposit after bilateral arteriographic control to exclude any remaining bleeding

cessible points, more distal (ideally exactly at bleeding point) and definitive treatment, and repeatability.

Another advantage described was the feasibility in local anesthesia, useful in hemodynamically unstable patients; but we know that $93 \%$ of this kind of facially injured patients will require definitive airways [9].

In patients who are hypersensitive to iodine and in case of ethmoidal arteries embolization, this treatment is not always feasible.

When used early, endovascular embolization is associated with high survival rates and low incidence of complications $[18,32]$.

Complications include fever, pain, trismus, cerebrovascular accidents, blindness, facial nerve palsy, seizures, soft tissue swelling, or necrosis. The overall complication rate is around $3-27 \%$ but most complications were minor and transient [33].

The femoral artery is cannulated with a $5 \mathrm{~F}$ diagnostic catheter equipped with a coaxial microcatheter for superselective embolization; materials generally used for hemostasis are cyanoacrylate 1:3 with Lipiodol glue and PVA particles (150-200 or 250-300 $\mu \mathrm{m}$ ) or a platinum micro-coil. The former is preferred in patients with direct identification of the bleeding point; the latter are the choices in on-field hemostasis when an angiography cannot identify a specific vascular lesion.

A formal preoperative bilateral internal-external diagnostic carotid arteriography is advisable; a post-procedure CT scan is recommended.

\subsubsection{End-Point-Guided Resuscitation}

Also in maxillofacial trauma management, damage control surgery is part of a strategy in which permissive resuscitation 

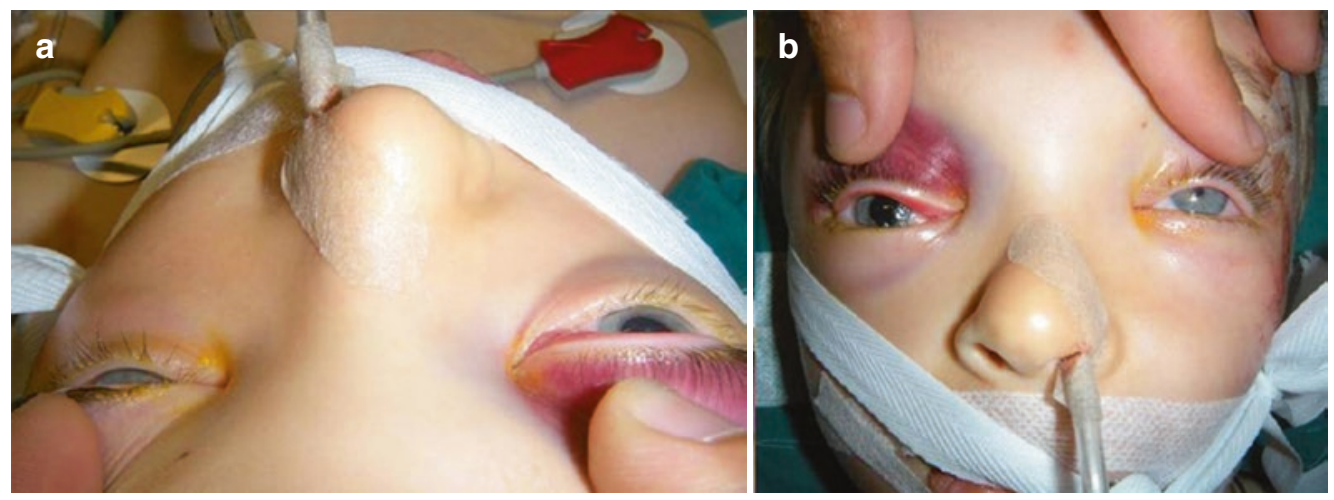

Fig. 12.6 (a) Right eye post-traumatic tense proptosis in an unconscious-intubated patient, due to right orbital compartment syndrome (upper retrobulbar hematoma). (b) Right eye caudal dystopia and a reagent right mydriasis in the same patient, confirming clinical suspicion of orbital compartment syndrome with targeted hypotension, early recognition of coagulopathy, and thromboelastography-guided point of care are equally necessary.

As in bleeding from extra-facial sites, the ideal systolic target is permissive value of $80 \mathrm{mmHg}$; bleeding may recommence as the blood pressure improves during resuscitation.

But every facial trauma suggests a cranial trauma until this is excluded. For this reason, general safety $100 \mathrm{mmHg}$ value is preferred.

\subsection{Eyes and Visual-Threatening Injuries}

\subsubsection{Clinical Assessment}

When $\mathrm{ABC}$ priorities have been dealt with, other treatments for facial injuries might be delayed for at least $24 \mathrm{~h}$, but visual-threatening conditions have to be rapidly detected and promptly managed [34]. This kind of approach can be resumed in the "ABCDEyes" work-up [35], performed toward the end of the primary survey.

Visual-threatening injuries are reported to occur in between 0.56 and $6 \%$ of facial fractures. Middle and upper thirds injuries are obviously those of interest [35].

In addition to direct eyeball injuries and loss of globe protection from adnexal wound laceration (see Chap. 13), the main causes of loss of vision are orbital compartment syndrome and traumatic optic neuropathy [36, 37].

Orbital contents are enclosed by a continuous coneshaped fascial envelope (Tenon's capsule) which reaches the eyelids and their bony insertions anteriorly [38].
The orbit anatomy creates a "closed room" with four bony walls and a fifth, soft but strong, anterior wall made of a fibrocartilaginous (septo-tarsal) structure, fixed by firm medial and lateral canthal ligaments. This anterior semiflexible wall resembles the orbit to other body sites prone to compartment syndrome [35, 38].

Another orbital anatomic peculiarity is the absence of lymphatic vessels; only inferior and superior ophthalmic veins can drain fluid form the orbit.

Physiological intraorbital pressure is about $3-6 \mathrm{mmHg}$; orbital perfusion pressure (to the retina and optic nerve) is the result of a difference between mean arterial pressure and this interstitial pressure value [39].

\subsubsection{Diagnosis}

Any causes of increased orbital contents volume (blood, swelling, emphysema, brain herniation) or blow-in bony fracture can raise intraorbital pressure until it reaches critical points, thus causing hypoperfusion or ischemia [40]. With similarities to traumatic brain injuries, mean arterial pressure critical reduction (hypovolemic shock, surgery, vasodilatation, or acute "pump" failure) can exasperate this equilibrium [35, 39].

If left untreated, damage becomes irreversible in 60-120 min [35, 41-43]. For this reason, early recognition and rapid management of orbital compartment syndrome is mandatory, although this must not interfere with any ongoing investigation and resuscitation.

Clinical signs are the best indicators of the onset of orbital compartment syndrome: progressive decrease of visual acuity with an enlarged blind spot on the visual field, red color 

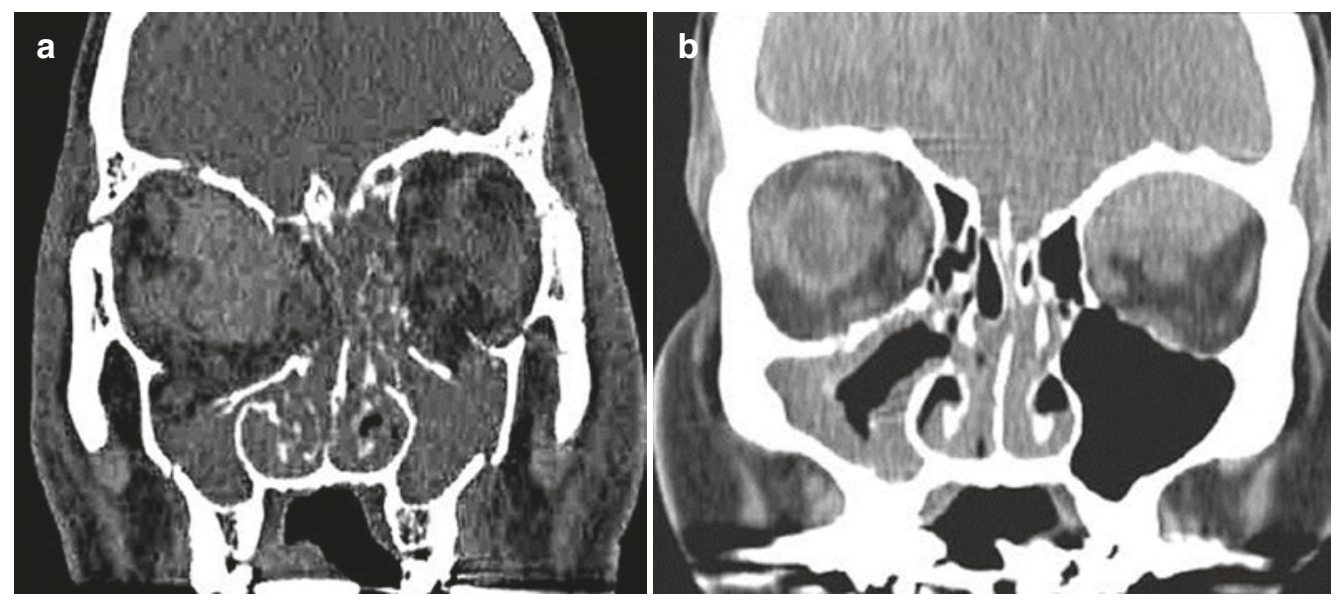

Fig. 12.7 (a) CT example of right superomedial intra-extraconal retrobulbar hematoma, coming from ciliary and ethmoidal arteries together. (b) CT demonstration of left upper extraconal retrobulbar hematomas, corresponding to linear fracture of left orbital roof

desaturation, tense proptosis resistant to manual retropulsion, relative afferent pupillary defect (RAPD) or Marcus Gunn pupil, orbital pain, ophthalmoplegia, conjunctival hemorrhages, and fundus oculi alterations are the most important of them [35, 40, 42, 44].

The crucial question to keep in mind is "Can the patient see?"

Any other signs could be trimmed down if no deterioration in visual acuity is shown after repeated evaluation.

Most of the patients have an altered consciousness, so proptosis, RAPD (Fig. 12.6a, b), and fundus alterations are the only clinical finding which can determine whether patients possibly need urgent treatment [35].

Proptosis has been reported to occur in up to $3 \%$ of blunt head injuries [45]. Acute traumatic proptosis may arise from blow-in fractures, retrobulbar hematoma, massive emphysema, and generalized retrobulbar swelling (accentuated in prolonged prone position or massive fluid resuscitation) [46].

In most cases proptosis is mild, and no active intervention is urgently required, other than regular reassessment [35] until its maximum expression (generally about $36 \mathrm{~h}$ after injury) $[39,42]$.

Warning is given in the presence of a "hard-stone" protruding eyeball which is resistant to reduction at gentle palpation (to avoid any uveal tissue prolapse from possible globe lacerations) compared with a non-injured site.

Emphysema is rarely the sole cause of compartment syndrome; in its presence, retinal ischemia occurs if intraorbital pressure values exceed a mean arterial pressure of 60-70 $\mathrm{mmHg}$ [46].

Retrobulbar hemorrhage, occurring in $0.3-1 \%$ of patients with orbitozygomatic fractures [36, 47], and generalized retrobulbar swelling are the most common causes of proptosis [39, 42]. Blow-in fractures can precipitate reducing orbital room volume.

Retrobulbar hemorrhages can be intra- or extraconal; the former are worse in prognosis because they originate from central retinal and ciliary arteries [35, 39] (Fig. 12.7ba9); their overall incidence of blindness is as high as $48 \%$ [47]. Extraconal ones derive from bony fractures, infra- or supraorbital artery damage, or muscle lacerations and are the main targets of surgical drainage (Fig. 12.7b).

As previously described the diagnosis of retrobulbar hematoma is primarily clinic, and in unconsciousness patients the presence of RAPD is one of the most sensitive indicators of aggressive urgent management needs [35, $42,48]$.

Pupillary light reaction is a component of " $\mathrm{D}$-disabilities" neurologic examination; it can be misinterpreted in the presence of direct injury of the globe (and ciliary muscle), alcohol, drugs, opiates, and paralyzing agents $[12,35]$.

Anisocoria is not a consequence of damage to the anterior visual pathway; even after unilateral cutting of the optic nerve, pupils remain symmetrical.

A reliable test for a primary diagnosis of optic nerve damage is the swinging flashlight test [49]: Just a "sluggish" response, although subjective, is accurate indicator of visual impairment [35]. 
In other words, only a brisk reaction to direct and consensual light stimuli in a round, concentric pupil can be a reliable way to exclude the necessity of emergency intervention [35].

Particular care is required in elderly patients, in which mild dilated and fixed pupil in a red-eye can be justified by an underling acute-angle glaucoma that can be worsened by drugs [35, 42].

A formal ophthalmologic evaluation is indicated in every patient with middle-upper third facial trauma; emergent examination is formally necessary only in patients with visual-threatening suspicion. It's imperative therefore to exclude sclero-conjunctival laceration, corneal wound, vitreous hemorrhages, retinal detachment, acute-angle glaucoma presence, lens dislocation, and hyphema before performing emergency surgical decompression.

Fundus evaluation is not just required to detect optic atrophy, which can be seen 4-17 days after injury, but also to check retinal vascularization (i.e., hemorrhages or venous congestion) [42].

Before starting surgical treatment, the real cause of proptosis should be ideally defined with CT. Any patient requiring a brain CT, who has suspected periorbital or ocular injuries, should undergo imaging of orbits at the same time [35].

Only a CT scan can identify the real etiology of orbital compartment syndrome.

Retrobulbar hematomas need to be evacuated with specific site incision [35, 38]; orbital compartment syndrome caused by swelling, diffuse bleeding into retrobulbar fat, or emphysema can be managed with a time-saving damage control anterior orbitotomy.

In case of blood collection, a CT also allows surgeons to choose the best (direct) access to drain it [39, 42]; generally, lateral (upper or lower lid) accesses are considered safer, and a precise preoperative imaging-guided strategy is important to avoid roaming in traumatized orbital anatomy.

In patients who are unstable or unresponsive to resuscitation, in whom the CT is skipped, and the patients sent to the operating room, lateral canthotomy with inferior cantholysis is the choice to save time also in case of an endoorbital hematoma. Definitive evacuation may be postponed to after a subsequent diagnostic phase $[36,42]$.

Clinical suspicion is particularly difficult in unconscious patients, in whom visual acuity deterioration cannot be proved. In hemodynamically stable patients, tonometry with portable devices, B-scan sonography [50], and flash-evoked visual potentials $[42,49,51]$ are more useful than fundus- copy, because the onset of anatomic alterations of the papilla needs time (7-14 days).

Tonometry, measured with portable device, is widely indicated in literature [35, 44, 47]. Normal intraocular pressure (IOP) is $10-20 \mathrm{mmHg}$ and may give some indications of intraorbital (retrobulbar) pressure, though it doesn't precisely reflect its measure [44, 47, 52].

Comparative measurements on both sides are indicated [39].

In a proptosed eye, an IOP of around $40 \mathrm{mmHg}$ or more indicates critical ischemia and the need for emergent treatment [42, 44, 53].

Flash visual evoked potentials have been reliable in checking the integrity of the visual pathway even in unconscious patients; unfortunately, the equipment is cumbersome for an emergency room [35, 50, 54].

They are useful also in traumatic optic neuropathy (TON), which can occur in $0.5-2 \%$ of head injuries, $2.5 \%$ of midface fractures, and $10 \%$ of major craniofacial injuries $[36,37,55]$.

TON must be suspected after trauma with visual loss and RAPD without direct globe involvement [37].

Most commonly the optic nerve is damaged posterior to the entry point of central retinal vessels, presenting a normal optic disk appearance. If damaged anterior to this point, the disk conversely will appear swollen with retinal hemorrhages [56].

TON can be direct or indirect, by the transmission of forces from a distant site; also it can be primary (with immediate sharing of retinal ganglion cell axons) or secondary (due to swelling of the nerve within inflexible orbital apex).

\subsubsection{Operative Management}

There are few emergency sight-saving procedures: anterior orbitotomy by lateral canthotomy and inferior cantholysis, protection of the globe following loss of eyelid integrity, irrigation if chemical injury is suspected, orbital apex decompression (via intracranial approach or by endoscopy), and hematoma evacuation [35].

Anterior orbitotomy by lateral canthotomy and inferior cantholysis (defined as surgical disinsertion of inferior crus of lateral canthal tendon) is the gold standard decompressive treatment to obtain a significative intraorbital pressure reduction $[35,36,38,39,42,43,53]$. Unfortunately this effect is transient in setting of continuous bleeding [52, 57]. 

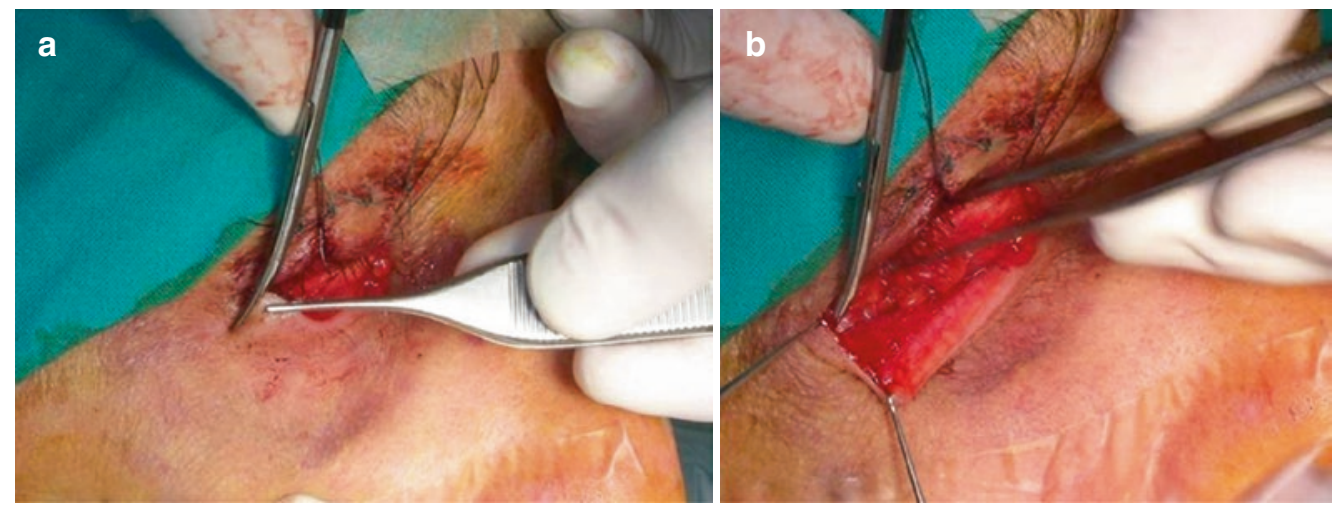

Fig. 12.8 (a) Right anterior orbitotomy by lateral canthotomy performed with a single, full thickness, $7 \mathrm{~mm}$ cut of the lower lid, leaving about $1 \mathrm{~mm}$ of the inferior crus inserted laterally. (b) Eversion of the loosened right lower lid facilitates septal plane dissection and its longitudinal incision (septolysis). Note also orbital fat herniation, meaning effective in intraorbital pressure release
Original technique can be done in the ER, with local anesthesia, and is carried out first by placing an artery clip at the lateral canthus, between the upper and lower lids, crushing the tissue beneath. Lateral canthal tendon incision is made horizontally at this level with iris scissors, with a length of $5-8 \mathrm{~mm}$; the inferior lateral crus of lateral canthal tendon is then completely disinserted, resulting in a totally mobile lower lid. The lateral canthal incision can be sutured later or commonly left to granulate $[38,53]$.

Some authors suggest additional septolysis in a suborbicularis muscle plane, to improve intraorbital pressure reduction up to $70 \%$ of the initial value, superior cantholysis, or endoscopic medial/inferior bony walls decompression (further $17 \%$ reduction in intraocular pressure from peak level) $[44,58,59]$.

Our modified technique consists in a single, full thickness, 5-8 mm cut of the lower lid (skin, muscle, septo-tarsal and conjunctival plane) placed as laterally as needed to leave about $1 \mathrm{~mm}$ of the inferior crus inserted. Eversion of the loosened lower lid facilitates septal plane dissection and its longitudinal incision (septolysis). Landmark 5/0 nylon stitches are placed on the "gray line", both medially and laterally to the incision, to facilitate postponed canthal repositioning and suture that always must be performed for better aesthetic results (Fig. 12.8).

To evacuate a superior-superolateral hematoma, generally a superior lid skin incision (in correspondence with the lateral third of orbito-palpebral sulcus, where levator palpebrae aponeurosis is not represented) and a supraorbicularis dissection straight to orbital margin is the safe way; bony margin is less than $15 \mathrm{~mm}$ from the skin incision, and here we can enter the orbital space to reach the blood collection (Fig. 12.9). A capillary drain can be placed for some days, skin secured with a single stitch, and the skin wound is sutured with 5-6/0 single nylon stitches or running suture.

Some authors suggest a lateral eyebrow incision, effective for lateral fluid collection but less ergonomic to reach orbital roof [60].

In the case of an inferior-inferolateral hematoma, a traditional subciliary approach is used; proptosis generally hind transconjunctival approach if no lateral canthotomy is prepared.

Hayter and Sugar in 1991 proposed a useful orbital postsurgical observation chart in which pain, acuity, proptosis, direct light reflex, and pupil size are carried out at 15-min intervals for the first $2 \mathrm{~h}$, then at 30-min intervals for the next $4 \mathrm{~h}$, and then hourly until further notice [61].

\subsubsection{Nonoperative Management}

In orbital compartment syndrome, additional medical treatment with acetazolamide $500 \mathrm{mg}$, either intravenous or intramuscular, and rapid infusion of $20 \%$ mannitol or corticosteroids should not delay surgery, and postoperative therapy is not indicated especially in patients with concomitant severe head trauma [43].

In traumatic optic neuropathy, primary injury is unavoidable, whereas minimizing secondary injuries is the rationale for every treatment. Despite this, no statistically significant benefit was demonstrated over conservative management, with either corticosteroid or surgical (intracranial or endoscopic) optic canal decompression $[37,62-65]$. 


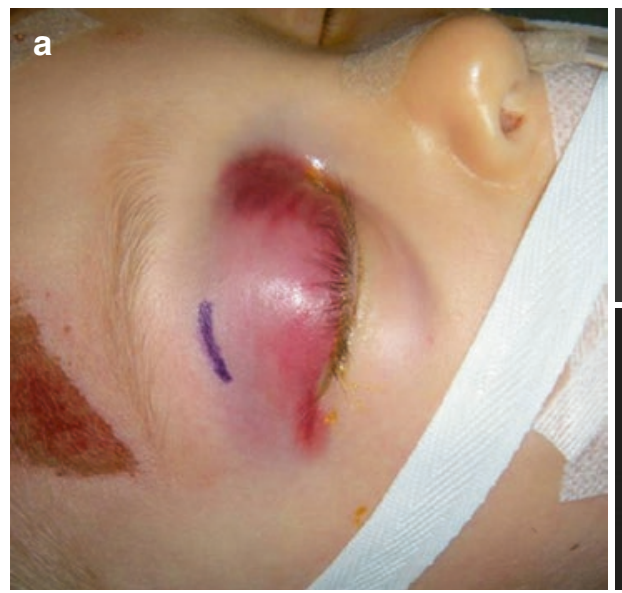

Fig. 12.9 (a) Lateral right upper lid $10 \mathrm{~mm}$ skin incision, to evacuate a retrobulbar hematoma coming from orbital roof fracture. Swelling can make it difficult to position the incision properly, just corresponding to orbito-palpebral sulcus; a contralateral one could be used as

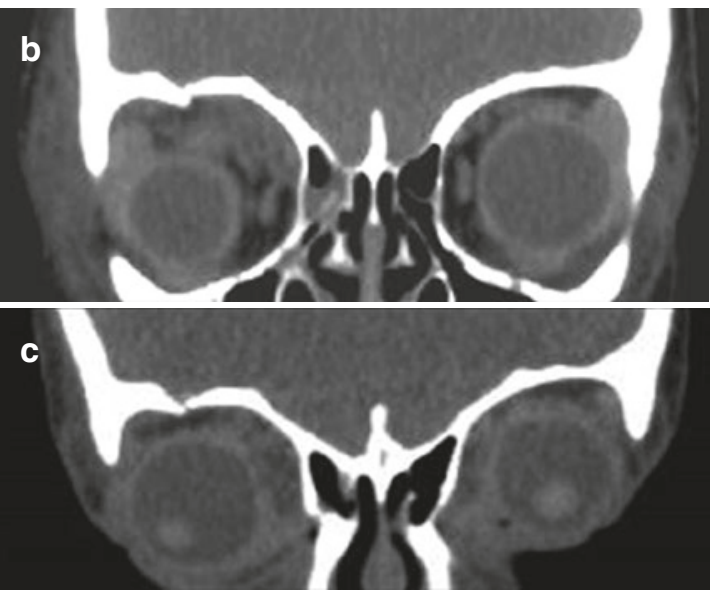

reference for normal distance to palpebral margin. (b) Preoperative CT location of retrobulbar hematoma, needed to choose the best ("straight to") access. (c) Postoperative CT control of complete surgical evacuation
TON has a high spontaneous visual recovery rate up to 40-60\% when managed conservatively; patients with direct optic nerve injury and no light perception at presentation have a poorer prognosis $[37,55]$.

Furthermore $40-70 \%$ of patients with traumatic optic neuropathy have loss of consciousness associated [37, 62], and CRASH trial revealed an increased risk of death in head trauma patients treated with steroids $[37,63,66]$; thus they remain unadvisable.

\subsubsection{Special Part: Orbital Trapdoor-Type Fractures in Children}

The last traumatic orbital urgency that must be discussed is wall fractures with entrapment of orbital contents. It's called a trapdoor-type fracture and generally involves the orbital floor.

This type of fracture is frequent in children because of their bone elasticity.

The direct transmission of forces from bone rims ("buckling theory") or the eyeball, via intraorbital soft tissues ("hydraulic theory"), can cause green-stick thinner orbital wall fracture that can allow orbital soft tissue herniation. Subsequent spontaneous elastic bone repositioning, pivoting around a bony hinge, entraps them and causes restricted eye movement with diplopia, pain during limited up-gaze, minimal conjunctival response ("white-eyed blowout" fractures, Fig. 12.10a), and sympathetic reflex activation.

The oculo-cardiac (Aschner-Dagnini) reflex is an infrequently observed subtype of trigemino-vagal reflex, and its clinical characteristics can include headache, gastric hypermobility with vomiting, apnea, bradycardia until asystole (1:3500), and arterial hypotension [67].

In unconscious patients clinical findings may be reduced to a restricted duction and traction test; it consists in a forced upward and downward eye movement, tested with forceps pinching rectus muscles insertion.

The relative paucity of clinical signs may delay diagnosis and compromise the result.

CT findings are equally poor and consist of a linear orbital floor fracture, without bone displacement, and a minimal amount of soft tissue lying below, outside the orbit, downward into the maxillary sinus ("teardrop sign") with a double-density sign representing a rim of hemorrhagic mucosa surrounding entrapped periorbital fat (Fig. 12.10b).

Definitive treatment is a specialized skill, but early recognition and timely resolution are strongly associated with significantly better outcomes [68]. 

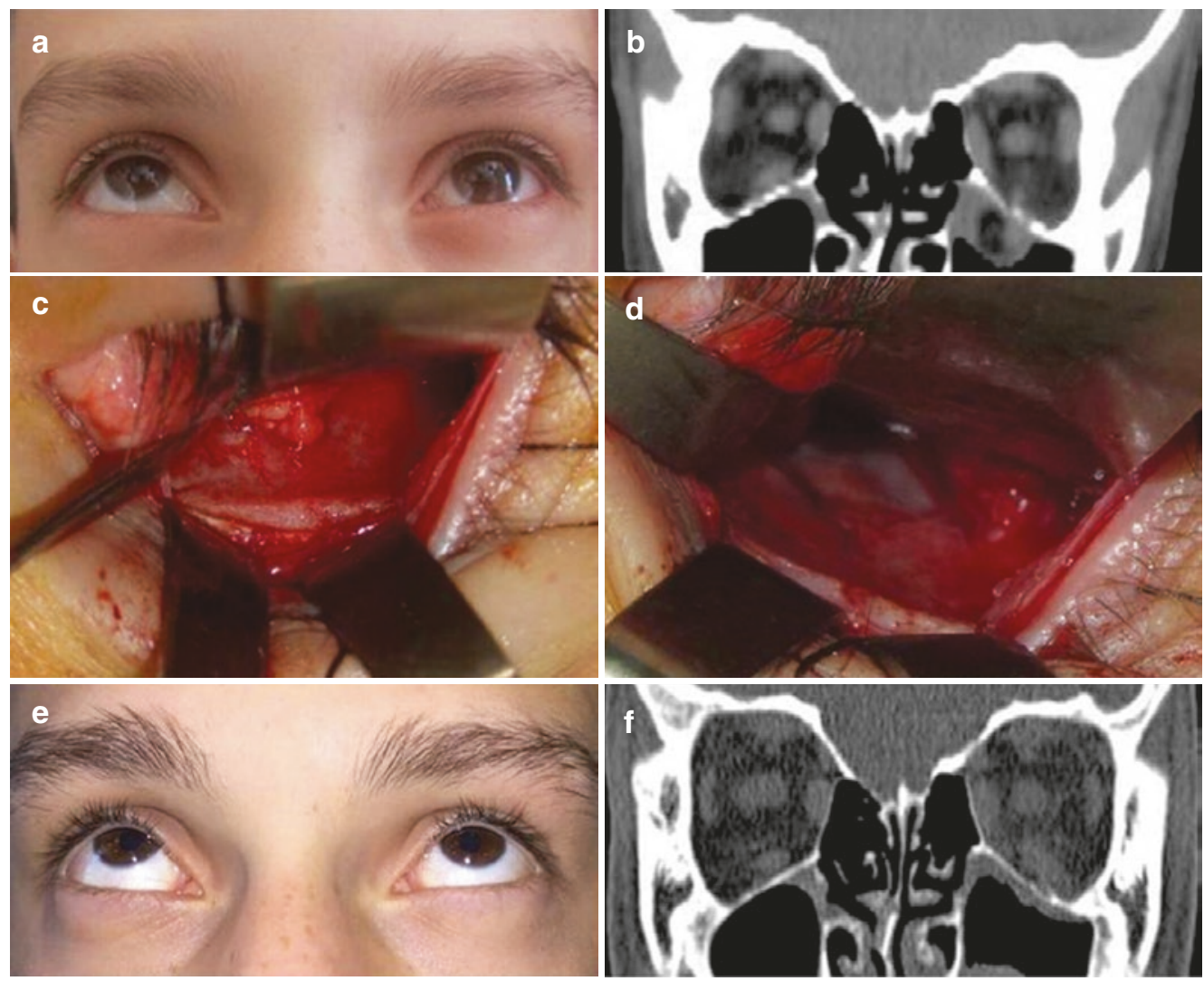

Fig. 12.10 (a) Left "white-eyed" trapdoor-type fracture of orbital floor, in 7-year-old boy with restricted eye movement, diplopia, pain during limited up-gaze, and minimal conjunctival response. (b) Preoperative CT showing "teardrop" with "double-density" sign. (c) Intraoperative picture in transconjunctival access and left orbital floor exploration; note herniation and entrapment of orbital content within the fracture. (d) Intraoperative picture of the same procedure, after

In case of doubt and stable/conscious patients, orthoptic evaluation with Hess-Lancaster test could give adjunctive information.

The resolution of an oculo-cardiac reflex could be a lifesaving emergency; however urgent muscular freeing avoids tissue ischemia and fibrosis causing irreversible scarring with persistent diplopia.

Surgery is done under general anesthesia, usually with lower lid transconjunctival-preseptal approach to inferior orbital rim and orbital floor. Subperiosteal dissection allows soft tissue reduction, after gentle bone fragment mobiliza-

reduction of end orbital tissue herniation; careful bone fragment repositioning avoids necessity of any further reconstruction, with a prefect continuity of orbital floor anatomy. (e) Postsurgical clinical resolution of any ocular movement restriction. (f) Postoperative CT control confirming proper reduction of soft tissue herniation and straight continuity of the left orbital floor reduced

tion. In pediatric patients, careful bone repositioning, generally, makes any further reconstruction unnecessary (Fig. 12.10c, d, f).

Conjunctival incision is generally closed with single or running sutures with $7 / 0$ resorbable poly-filament suture. An intraoperative postreduction forced duction test must show a release of any ocular movement restriction.

Clinical signs generally have an immediate resolution (Fig. 12.10e), and the patient could be followed with the previously described Hayter and Sugar orbital postsurgical observation chart [61]. 


\section{Case Scenario}

A 21-year-old male who fell from about $15 \mathrm{~m}$. Paramedics found him conscious, with profuse epistaxis and oral bleeding, evident traumatic facial involvement, and abdominal pain.

Hemodynamically stable, in less than $15 \mathrm{~min}$, he was admitted to trauma center ER, and airways were immediately secured with the orotracheal tube. E-FAST and thorax and pelvic X-rays showed free fluid collected in the abdomen, complex pelvic "open-book" fracture, and right pneumothorax with mild mediastinum shift. Hemodynamics worsened, so a pelvic binder was positioned and transfusion protocol contemporary was started.

1. What's the priority?

A. To control orofacial bleeding

B. Get CT scan of the face because of possible eyes involvement with threatening visual lesions

C. Thorax drainage and simultaneous anterior nasal packing positioning

D. Remove pelvic binder and perform extraperitoneal abdominal packing

Hemodynamic stability was gained and patient could be transferred to $\mathrm{CT}$ to get total body triphasic examination.

2. What to do about facial imaging?

A. Facial examination must be postponed because of relative stability of hemodynamic. Only the brain, thorax, and abdomen are priorities in emergency setting.

B. Facial fractures could be studied with traditional $\mathrm{X}$-rays, during pelvic and thoracic evaluation at primary survey.

C. Brain TC $5 \mathrm{~mm}$ slices allow to properly evaluate facial fracture at the same time.

D. Thin-slice (1 mm or less) facial CT scan is the gold standard in middle third/orbital/complex facial fractures; its acquisition never significantly increases diagnostic time.
CT showed bilateral lung contusion, hepatic laceration, left kidney artery dissection, active arterial blushing from left gluteal artery, a complex pelvic fracture, and the presence of subdiaphragmatic free air. Contemporary facial CT demonstrated multifragmentary comminuted fracture of the middle third (with bilateral maxillary sinus involvement and maxillary intrusion) and mandibular symphyseal fracture.

Oropharyngeal inspection revealed a mild but persistent posterior epistaxis, despite bilateral anterior nasal packing.

3. How to get better local hemostatic control?

A. Increasing the volume of bilateral anterior nasal packing

B. With diathermocoagulation of nasal mucosa with nasal speculum and suction

C. Performing anterior-posterior nasal packing with silicone dual lumen devices with separate inflating balloons

D. Removing anterior nasal packing and performing oropharyngeal packing with gauzes

Patient then went to OR to perform damage control laparotomy, angiography, and embolization of left gluteal artery and pelvic anterior external fixation.

4. What else about facial fractures?

A. Bleeding from jaw fractures into oral cavity may be treated conservatively with nonoperative management, until definitive surgery, because this is rarely a cause of hemodynamic instability.

B. Facial fractures need to be treated immediately because they are exposed and bleeding.

C. Facial damage control (manual reduction and temporary stabilization with iron wiring of bone fractures and suture of intra-extraoral wounds) must be done quickly and simultaneously to other maneuvers.

D. Facial damage control always must follow neurosurgical and thoracoabdominal emergency surgery. 
Patient was therefore transferred to IC unit; at $16 \mathrm{~h}$ from admission, his systolic blood pressure raised up to normal level and moderate but persistent rhinopharyngeal bleeding starts over.

5. What's definitive control of facial bleeding?

A. Bilateral surgical ligation of external carotid arteries to prevent collateral circulation and bleeding relapse
B. Diagnostic angiography and superselective embolization with coaxial microcatheter

C. Angio-CT scan demonstration of maxillary artery involvement and its transantral endoscopic ligation

D. To reduce systolic pressure resuscitation target (permissive resuscitation) to allow spontaneous hemostasis

Please see Chap. 58 for the correct answer.

\section{References}

1. Boffano P, Roccia F, Zavattero E, Dediol E, Uglešić V, Kovačič Ž, Vesnaver A, Konstantinović VS, Petrović M, Stephens J, Kanzaria A, Bhatti N, Holmes S, Pechalova PF, Bakardjiev AG, Malanchuk VA, Kopchak AV, Galteland P, Mjøen E, Skjelbred P, Koudougou C, Mouallem G, Corre P, Løes S, Lekven N, Laverick S, Gordon P, Tamme T, Akermann S, Karagozoglu KH, Kommers SC, Forouzanfar T. European Maxillofacial Trauma (EURMAT) project: a multicentre and prospective study. J Craniomaxillofac Surg. 2015;43:62-70.

2. Hutchinson I, Lawlor M, Skinner D. ABC of major trauma. Major maxillofacial injuries. Br Med J. 1990;301:595-9.

3. Perry M, Morris C. Advanced trauma life support (ATLS) and facial trauma: can one size fit all? Part 2: ATLS, maxillofacial injuries and airway management dilemmas. Int J Oral Maxillofac Surg. 2008;37:309-20.

4. Jose A, Nagori SA, Agarwal B, Bhutia O, Roychoudhury A. Management of maxillofacial trauma in emergency: an update of challenges and controversies. J Emerg Trauma Shock. 2016;9:73-80.

5. Ardekian L, Samet N, Shoshani Y, Taicher S. Life-threatening bleeding following maxillofacial trauma. J Craniomaxillofac Surg. 1993;21:336-8.

6. Perry M, O'Hare J, Porter G. Advanced Trauma Life Support (ATLS) and facial trauma: can one size fit all? Part 3: hypovolaemia and facial injuries in the multiply injured patient. Int $\mathrm{J}$ Oral Maxillofac Surg. 2008;37:405-14.

7. Ceallaigh PO, Ekanaykaee K, Beirne CJ, Patton DW. Diagnosis and management of common maxillofacial injuries in the emergency department. Part 1: advanced trauma life support. Emerg Med J. 2006;23:796-7.

8. Veeravagu A, Joseph R, Jiang B, Lober RM, Ludwig C, Torres R, Singh H. Traumatic epistaxis: skull base defects, intracranial complications and neurosurgical considerations. Int J Surg Case Rep. $2013 ; 4: 656-61$.
9. Khanna S, Dagum AB. A critical review of the literature and an evidence-based approach for life-threatening hemorrhage in maxillofacial surgery. Ann Plast Surg. 2012;69:474-8.

10. Bynoe RP, Kerwin AJ, Parker HH 3rd, Nottingham JM, Bell RM, Yost MJ, Close TC, Hudson ER, Sheridan DJ, Wade MD. Maxillofacial injuries and life-threatening hemorrhage: treatment with transcatheter arterial embolization. J Trauma. 2003;55:74-9.

11. Tung TC, Tseng WS, Chen CT, Lai JP, Chen YR. Acute life-threatening injuries in facial fracture patients: a review of 1,025 patients. J Trauma. 2000;49:420-4.

12. Perry M, Dancey A, Mireskandari K, Oakley P, Davies S, Cameron $\mathrm{M}$. Emergency care in facial trauma-a maxillofacial and ophthalmic perspective. Injury. 2005;36:875-96.

13. Ho K, Hutter JJ, Eskridge J, Khan U, Boorer CJ, Hopper RA, Deva AK. The management of life-threatening haemorrhage following blunt facial trauma. J Plast Reconstr Aesthet Surg. 2006;59:1257-62.

14. Gwyn PP, Carraway JH, Horton CE, Adamson JE, Mladick RA. Facial fractures - associated injuries and complications. Plast Reconstr Surg. 1971;47:225-30.

15. Shimoyama T, Kaneko T, Horie N. Initial management of massive oral bleeding after midfacial fracture. J Trauma. 2003;54:332-6; discussion 336.

16. Singam P, Thanabalan J, Mohammed Z. Superselective embolisation for control of intractable epistaxis from maxillary artery injury. Biomed Imaging Interv J. 2011;7:1-3.

17. Al-Jehani HM, Alwadaani HA, Almolani FM. Traumatic intracranial internal carotid artery pseudoaneurysm presenting as epistaxis treated by endovascular coiling. Neurosciences (Riyadh). 2016;21:60-3.

18. Cogbill TH, Cothren CC, Ahearn MK, Cullinane DC, Kaups KL, Scalea TM, Maggio L, Brasel KJ, Harrison PB, Patel NY, Moore EE, Jurkovich GJ, Ross SE. Management of maxillofacial injuries with severe oronasal hemorrhage: a multicenter perspective. J Trauma. 2008;65:994-9.

19. Waldron J, Stafford N. Ligation of the external carotid artery for severe epistaxis. J Otolaryngol. 1992;21:249-51. 
20. Zachariades N, Rallis G, Papademetriou G, Papakosta V, Spanomichos G, Souelem M. Embolization for the treatment of pseudoaneurysm and transection of facial vessels. Oral Surg Oral Med Oral Pathol Oral Radiol Endod. 2001;92:491-4.

21. Lynham AJ, Hirst JP, Cosson JA, Chapman PJ, McEniery P. Emergency department management of maxillofacial trauma. Emerg Med Australas. 2004;16:7-12.

22. Sakamoto T, Yagi K, Hiraide A, Takasu A, Kinoshita Y, Iwai A, Yoshioka T, Sugimoto T. Transcatheter embolization in the treatment of massive bleeding due to maxillofacial injury. J Trauma. 1988;28(6):840-3.

23. Gamanagatti S, Prasad TV, Kumar A, Singhal M, Sagar S. Angioembolisation in maxillofacial trauma: an initial experience in a tertiary care center. J Maxillofac Oral Surg. 2016;15:59-66.

24. Buchanan RT, Holtmann B. Severe epistaxis in facial fractures. Plast Reconstr Surg. 1983;71:768-71.

25. Rockey JG, Anand R. A critical audit of the surgical management of intractable epistaxis using sphenopalatine artery ligation/diathermy. Rhinology. 2002;40:147-9.

26. Srinivasan V, Sherman IW, O'Sullivan G. Surgical management of intractable epistaxis: audit of results. J Laryngol Otol. 2000;114:697-700.

27. Baqain ZH, Thakkar C, Kalavrezos N. Superselective embolization for control of facial haemorrhage. Injury. 2004;35:435-8.

28. Goddard JC, Reiter ER. Inpatient management of epistaxis: outcomes and cost. Otolaryngol Head Neck Surg. 2005;132: 707-12.

29. Zhang C, Xie X, You C, Mao B, Wang C, He M, Sun H. Endovascular treatment of traumatic pseudoaneurysm presenting as intractable epistaxis. Korean J Radiol. 2010;11:603-11.

30. Radvany MG, Gailloud P. Endovascular management of neurovascular arterial injuries in the face and neck. Semin Intervent Radiol. 2010;27:44-54.

31. Sokoloff J, Wickbom I, McDonald D, Brahme F, Goergen TC, Goldberger LE. Therapeutic percutaneous embolization in intractable epistaxis. Radiology. 1974;111:285-7.

32. Liao CC, Hsu YP, Chen CT, Tseng YY. Transarterial embolization for intractable oronasal hemorrhage associated with craniofacial trauma: evaluation of prognostic factors. J Trauma. 2007;63:827-30.

33. Scaramuzzi N, Walsh RM, Brennan P, Walsh M. Treatment of intractable epistaxis using arterial embolization. Clin Otolaryngol Allied Sci. 2001;26:307-9.

34. Perry M. Advanced Trauma Life Support (ATLS) and facial trauma: can one size fit all? Part 1: dilemmas in the management of the multiply injured patient with coexisting facial injuries. Int J Oral Maxillofac Surg. 2008;37:209-14.

35. Perry M, Moutray T. Advanced Trauma Life Support (ATLS) and facial trauma: can one size fit all? Part 4: 'can the patient see?' Timely diagnosis, dilemmas and pitfalls in the multiply injured, poorly responsive/unresponsive patient. Int J Oral Maxillofac Surg. 2008;37:505-14.

36. McClenaghan FC, Ezra DG, Holmes SB. Mechanisms and management of vision loss following orbital and facial trauma. Curr Opin Ophthalmol. 2011;22:426-31.

37. Steinsapir KD, Goldberg RA. Traumatic optic neuropathy: an evolving understanding. Am J Ophthalmol. 2011;151:928-33.

38. Winterton JV, Patel K, Mizen KD. Review of management options for a retrobulbar hemorrhage. J Oral Maxillofac Surg. 2007;65:296-9.

39. Allen M, Perry M, Burns F. When is a retrobulbar haemorrhage not a retrobulbar haemorrhage? Int J Oral Maxillofac Surg. 2010;39:1045-9.

40. Popat H, Doyle PT, Davies SJ. Blindness following retrobulbar haemorrhage - it can be prevented. Br J Oral Maxillofac Surg. 2007;45:163-4.
41. Hislop WS, Dutton GN, Douglas PS. Treatment of retrobulbar haemorrhage in accident and emergency departments. Br J Oral Maxillofac Surg. 1996;34:289-92.

42. Perry M. Acute proptosis in trauma: retrobulbar hemorrhage or orbital compartment syndrome-does it really matter? J Oral Maxillofac Surg. 2008;66(9):1913-20.

43. Soare S, Foletti JM, Gallucci A, Collet C, Guyot L, Chossegros C. Update on orbital decompression as emergency treatment of traumatic blindness. J Craniomaxillofac Surg. 2015;43: 1000-3.

44. Mohammadi F, Rashan A, Psaltis A, Janisewicz A, Li P, El-Sawy $T$, Nayak JV. Intraocular pressure changes in emergent surgical decompression of orbital compartment syndrome. JAMA Otolaryngol Head Neck Surg. 2015;141:562-5.

45. Kulkarni AR, Aggarwal SP, Kulkarni RR, Deshpande MD, Walimbe PB, Labhsetwar AS. Ocular manifestations of head injury: a clinical study. Eye (Lond). 2005;19:1257-63.

46. Linberg JV. Orbital compartment syndromes following trauma. Adv Ophthalmic Plast Reconstr Surg. 1987;6:51-62.

47. Fattahi T, Brewer K, Retana A, Ogledzki M. Incidence of retrobulbar hemorrhage in the emergency department. J Oral Maxillofac Surg. 2014;72:2500-2.

48. Chen YA, Singhal D, Chen YR, Chen CT. Management of acute traumatic retrobulbar haematomas: a 10-year retrospective review. J Plast Reconstr Aesthet Surg. 2012;65:1325-30.

49. Schumann P, Kokemüller H, Tavassol F, Lindhorst D, Lemound J, Essig H, Rücker M, Gellrich NC. Optic nerve monitoring. Craniomaxillofac Trauma Reconstr. 2013;6:75-86.

50. Kniess CK, Fong TC, Reilly AJ, Laoteppitaks C. Early detection of traumatic retrobulbar hemorrhage using bedside ocular ultrasound. J Emerg Med. 2015;49:58-60.

51. Cornelius CP, Altenmüller E, Ehrenfeld M. The use of flash visual evoked potentials in the early diagnosis of suspected optic nerve lesions due to craniofacial trauma. J Craniomaxillofac Surg. 1996;24:1-11.

52. Zoumalan CI, Bullock JD, Warwar RE, McCulley TJ. Evaluation of intraocular and orbital pressure in the management of orbital hemorrhage: an experimental model. Arch Ophthalmol. 2008;126:1257-60.

53. Goodall KL, Brahma A, Bates A, Leatherbarrow B. Lateral canthotomy and inferior cantholysis: an effective method of urgent orbital decompression for sight threatening acute retrobulbar haemorrhage. Injury. 1999;30:485-90.

54. Ikejiri M, Adachi-Usami E, Mizota A, Tsuyama Y, Miyauchi O, Suehiro S. Pattern visual evoked potentials in traumatic optic neuropathy. Ophthalmologica. 2002;216:415-9.

55. Steinsapir KD, Goldberg RA. Traumatic optic neuropathy: a critical update. Comp Ophtalmol Update. 2005;6:11-21.

56. Warner N, Eggenberger E. Traumatic optic neuropathy: a review of the current literature. Curr Opin Ophthalmol. 2010;21:459-62.

57. Sun MT, Chan WO, Selva D. Traumatic orbital compartment syndrome: importance of the lateral canthomy and cantholysis. Emerg Med Australas. 2014;26:274-8.

58. Oester AE Jr, Fowler BT, Fleming JC. Inferior orbital septum release compared with lateral canthotomy and cantholysis in the management of orbital compartment syndrome. Ophthal Plast Reconstr Surg. 2012;28:40-3.

59. Haubner F, Jägle H, Nunes DP, Schleder S, Cvetkova N, Kühnel T, Gassner HG. Orbital compartment: effects of emergent canthotomy and cantholysis. Eur Arch Otorhinolaryngol. 2015;272: 479-83.

60. Ghufoor K, Sandhu G, Sutcliffe J. Delayed onset of retrobulbar haemorrhage following severe head injury: a case report and review. Injury. 1998;29:139-41.

61. Hayter JP, Sugar AW. An orbital observation chart. Br J Oral Maxillofac Surg. 1991;29:77-9. 
62. Steinsapir KD. Treatment of traumatic optic neuropathy with highdose corticosteroid. J Neuroophthalmol. 2006;26:65-7.

63. Yu-Wai-Man P, Griffiths PG. Steroids for traumatic optic neuropathy.Cochrane Database Syst Rev. 2011;(19):CD006032. https://doi. org/10.1002/14651858.CD006032.pub3.

64. Levin LA, Beck RW, Joseph MP, Seiff S, Kraker R. The treatment of traumatic optic neuropathy: the International Optic Nerve Trauma Study. Ophthalmology. 1999;106:1268-77.

65. Lee V, Ford RL, Xing W, Bunce C, Foot B. Surveillance of traumatic optic neuropathy in the UK. Eye (Lond). 2010;24:240-50.

66. Edwards P, Arango M, Balica L, Cottingham R, El-Sayed H, Farrell B, Fernandes J, Gogichaisvili T, Golden N, Hartzenberg B, Husain M, Ulloa MI, Jerbi Z, Khamis H, Komolafe E, Laloë V, Lomas G,
Ludwig S, Mazairac G, Muñoz Sanchéz Mde L, Nasi L, Olldashi F, Plunkett P, Roberts I, Sandercock P, Shakur H, Soler C, Stocker R, Svoboda P, Trenkler S, Venkataramana NK, Wasserberg J, Yates D, Yutthakasemsunt S, CRASH trial collaborators. Final results of MRC CRASH, a randomised placebo-controlled trial of intravenous corticosteroid in adults with head injury-outcomes at 6 months. Lancet. 2005;365:1957-9.

67. Sires BS, Stanley RB Jr, Levine LM. Oculocardiac reflex caused by orbital floor trapdoor fracture: an indication for urgent repair. Arch Ophthalmol. 1998;116:955-6.

68. Gerbino G, Roccia F, Bianchi FA, Zavattero E. Surgical management of orbital trapdoor fracture in a pediatric population. J Oral Maxillofac Surg. 2010;68:1310-6. 